\title{
La fe en el Dios crucificado. Reflexiones desde El Salvador*
}

\author{
Jon Sobrino \\ Centro de Reflexión Teológica, \\ San Salvador.
}

En este seminario sobre La liberación de los pueblos y su difícil historia me han pedido que aborde el tema de la liberación desde la perspectiva teologal de un Dios crucificado. En otras palabras, cómo el Dios cristiano acompaña a los pueblos crucificados - con lo cual se está apuntando a la salvación-, y cómo la crucifixión de esos pueblos ${ }^{1}$ le afecta al mismo Dios —con lo cual se está remitiendo al misterio de Dios, un Dios crucificado.

Pienso también que, aunque la ocasion es académica, la expectativa es existencial, y quizás pudiera quedar expresada en estas sencillas palabras: "¿cómo es posible creer en Dios después del Sumpul y del Mozote?". O todavía en forma más directa: "¿en qué Dios - si en alguno- cree usted después de haber vivido estos horrores?". Y esta expectativa, por cierto, me parece la más adecuada para no convertir esta conferencia en puro discurso de ágora ateniense: "a ver qué nos dicen hoy acerca de Dios y acerca de pueblos lejanos", pues, si así fuese, no sólo se trivializarfa un problema sumamente grave, sino que incluso se dificultaría la comprensión teórica del asunto al no existir la empatía mínima necesaria. En otras palabras, faltaría el interés adecuado que mueve a conocer adecuadamente.

Todo eso significa que vamos a abordar el tema desde la realidad de la fe especffica que surge $\longrightarrow$ se desvanece- en medio de los procesos de liberación

* Este artículo es la reelaboración de una ponencia pronunciada en un seminario sobre La liberación de los pueblos y su dificil historia, el 9 de diciembre de 1993 en la Universidad Internacional Menéndez Pelayo, Valencia. 
y de la fe que tiene por objeto no sólo a Dios, sino a un Dios crucificado, todo lo cual supone novedad en la fe, y una novedad que afecta tanto a la oscuridad como a la autenticidad de esa fe. De esa fe pueden participar cristianos de la base, campesinos, hombres y mujeres sencillas, y también líderes religiosos, pastores y pensadores más estudiados. Son, pues, formas de fe histórica y existencialmente distintas, pero que pueden convergir de modo que "unos y otros se lleven mutuamente en la fe", como de hecho ocurre.

Digamos desde el principio que lo que más llama la atención de esa fe en el Dios crucificado es su oscuridad, y eso en ambos casos, entre los creyentes sencillos y entre los estudiados. El que para la religiosidad popular Dios sea "algo epidérmico," como dice frei Betto, es verdad, pero eso no quiere decir que la gente sencilla, en medio de torturas y masacres, no se pregunte "dónde está Dios". Y, por otra parte, aunque la le y la increencia no hayan sido temas muy explícilamente tratados por la teología de la liberación, no quiere esto decir que los teólogos no perciban con la razón - y sientan en su carne- el problema o el misterio de Dios, y que incluso lo perciban con mayor fuerza que en orras partes, pues es precisamente en el tercer mundo - mucho más que en otros mundos- donde se da con mayor estrépito la escandalosa paradoja de confesar a un Dios de vida y liberador de las víctimas, y de constatar que en la historia hay más injusticia que liberación ${ }^{2}$.

Pero también sorprende, como buena noticia, la hondura de esa fe, que ha llegado hasta el martirio. En otras palabras, en el contexıo de crucifixión hisıórica y teologal, el absurdo y la oscuridad no han apagado la luz, el miedo y la desesperación no han matado la esperanza, la injusticia y la muerte no han hecho desaparecer el amor, el compromiso y la vida.

Esta fe en el Dios crucificado es lo que queremos analizar a continuación. Queremos hacerlo con la mayor honradez posible, no de forma acrítica, pues, con razón, nos lo echaría en cara la modernidad. Pero queremos hacerlo también y sobre todo con hondura existencial para no caer en la banalidad y en el distanciamiento opcional de estos problemas, a lo que parecerfa inclinarnos la posmodernidad. En otras palabras, queremos dar razón de nuestra esperanza (1Pedr 3, 15).

\section{Cómo hablar de la fe en un Dios crucifícado}

Antes de analizar lo que hay de fe en un Dios crucificado y cómo los creyentes pueden experimentar liberación en ese Dios, digamos una palabra sobre el método que guía estas reflexiones, explicación nada superflua y menos en este caso, pues si siempre es difícil encontrar un modo apto para hablar de Dios mucho más lo será cuando se trata de un Dios crucificado.

a) Comencemos diciendo que nuestra reflexión está basada en directo en la 
realidad de los procesos históricos y sólo ulteriormente en conceptos previos a ella. Es, pues, una reflexión más de tipo histórico que doctrinal. En este sentido hay que tomar en serio el subtítulo de este escrito la experiencia salvadoreña, sin convertirla en un puro caso que se adujese para ilustrar un concepto universal, cuyo contenido ya serla conocido previamente. Y llamamos la atención sobre este punto, porque, aunque teóricamente se insiste en que toda teología cristiana debe ser histónica, esto no ocurre con frecuencia, sino que problentas reales suelen ser abordados muchas veces solo conceptual o doctrinalmente.

Somos conscientes, por supuesto, de que toda reflexión se hace dentro del círculo hermenéutico y de que para abordar cualquier realidad se necesita algún concepto previo. Creemos también que la historia y la experiencia deben ser conceptualizadas, no sólo narradas, pero insistimos en que lo que hay que elevar a concepto es la realidad de la historia y de la experiencia, y no otro concepto ya dado. Por ello, damos por supuestos los enfoques conceptuales brblicos, dogmáticos y teológicos sobre Dios y sobre un Dios cnucificado ${ }^{3}$, pero no nos basamos en ellos. Queremos, pues, elevar a concepto no simplemente otro concepto, por venerable que sea, sino la realidad, en este caso, veinte años de historia salvadoreña*.

Al abordar el tema del Dios crucificado es, pues, bueno y necesario tener en cuenta tradiciones como las paulinas y marcanas sobre la presencia y el silencio de Dios en la cruz de Jesús, "el viernes santo especulativo" de Hegel, el "sólo un Dios que sufre puede salvamos" de Bonhoeffer o el importante libro de J. Moltmann El Dios crucificados. Y por lo que se refiere al modo cómo la cruz afecta al quehacer teológico es bueno y necesario dejarse cuestionar por la pregunta de J. B. Metz "cómo hacer teología después de Auschwitz". Todo ello es importante para ubicar las preguntas de hoy en el contexto de la mejor tradición y para encontrar en ella conceptos que ayuden a ponernos en una pista correcta para dar una respuesta. Pero, aunque bueno y necesario, no es suficiente, y ello por una doble razón.

La primera es que se trata de textos del pasado, mientras la pregunta sigue resonando en el presente y lo hace, específicamente, como pregunta del presente, es decir, pregunta nunca acallada a pesar de que en el pasado ya hubiera respuestas a preguntas semejantes. Y la segunda es que ni siquiera los más vigorosos textos - sean del pasado o del presente - tienen, en cuanto textos, suficiente capacidad para movilizar el espíritu humano y creyente de forma adecuada en la búsqueda de una respuesta. Esa fuerza para preguntar y para responder sólo proviene de la misma realidad".

b) Si esto es verdad de cualquier conceptualización y si, por otra parte, todo hablar sobre Dios y sobre un "Dios crucificado" produce una especie de vérligo metafisico, entonces, por necesidad, en nuestra reflexión tenemos que mantenernos lo más ajustadamente posible a la realidad sin precipitarnos a elevarnos al 
puro concepto. Por esa razón, vamos a explicar brevernente por qué partimos de y procuramos mantenernos apegados a la realidad al hablar del Dios crucificado antes de elevarlo a concepto -aunque el lector no interesado en cuestiones metodologicas puede pasar al siguiente apartado.

En principio hay que afirmar la prioridad de la realidad sobre la interpretación que se haga sobre ella, lo cual es aceptado hoy por la teología de la liberaci6n? y algunas de las europeas". Hay, pues, prioridad logica de la realidad sobre el concepto', lo cual significa en nuestro caso el tenémoslas que haber con los procesos de liberación para ver si en ellos hay y qué en concreto de fe en un Dios crucificado, y qué de ese Dios es caplado como liberador, antes que imponer conceptos a la realidad para interpretarla.

Pero además de esta afirmación general, hay que insistir en que incluso cuando ya hay conceptos y textos teológicos iluminadores, éstos no parecen poder ser la base fundamental de la reflexión al menos en estos dos casos. El primero es cuando la realidad emerge históricamente en forma de grandes novedades, y el segundo cuando reológicamente se quieren conceptualizar realidades límile (Dios y fe), y realidades reduplicativamente límite (un Dios crucificado y fe en ese Dios). En esos casos, el concepto y el texto pueden ser de utilidad, pero no pueden sustituir al confrontarse directamente con la realidad. El peso de la realidad en sí misma y la fuerza de la realidad para mover al ser humano no pueden ser sustituidos por ningún concepto, aunque ya existan éstos y siempre sean útiles buenos conceptos previos.

Dicho en otras palabras, cuando la teología europea se pregunta cómo hacer teología después de Auschwitz está presuponiendo que hay que hacer un esfuerzo por tener noticia - ya sea por experiencia propia, por testimonio de otros o al menos por referencia documental - de dicha realidad, pues de otra forma no tendría sentido lógico la preocupación mentada, y está presuponiendo también que la realidad de Auschwitz, en cuanto realidad, es la que forzará a la teología a proceder de una determinada forma, o la que la empujará al silencio. Si esto es así, se comprenderá que con mucha más razón habrá que preguntarse por Auschwitz - léase, entre nosotros, masacre del Sumpul y del Mozote, asesinato de Monseñor Romero y de Ignacio Ellacurfa, de los líderes del Frente Democrático Revolucionario y de los sindicalistas de FENASTRAS, de los campesinos de Aguilares y de El Junquillo...- si se quiere hacer teologia cuando estamos en medio de Auschwitz.

Cuando se dan tales realidades en el presente, sería desatino e irresponsabilidad que la teología se basase sólo en el concepto, ni siquiera sólo en conceptos obtenidos a partir de situaciones semejantes, sin confrontarse directamente con la realidad presente. $\mathrm{Y}$ es que, por decirlo de alguna manera, en el concepto se puede considerar su contenido formal y su peso material. Lo primero puede ser conseguido en base a realidades del pasado, siempre que exista alguna analogía 
entre ellas y el presente. Lo segundo, sin embargo, depende esencialmente del dejarse afectar por la realidad. No es lo mismo, nos dice el sentido de realidad y el sentido común, hacer teología después de Auschwitz o de oídas de lo ocurrido en Auschwitz que en medio de Auschwitz, tocando y sintiendo su realidad. Sin referencia esencial a la historia real, sobre en todo en casos como éstos, la teología cae en inanidad, y, casi por necesidad, en diletantismo.

Si nos hernos extendido en este preámbulo metodológico es para que se entienda bien lo que vamos a decir a continuación. En definitiva, vamos a argumentar con la realidad, lo cual no quiere decir que nuestra reflexión no esté sujeta a la crítica, por supuesto, pero quiere decir que en último térnino es argumentación indefensa, que sólo podrá ser captada en base a algún contacto - aunque sea análogo - con la realidad crucifícada del tercer mundo.

Y digamos, de pasada, que quizás desde aquí se aprecie mejor la repetida afirmación de que el realismo filośfico zubiriano ayudó a Ellacurla a elaborar su propia teología de la liberación, "elevando la realidad a concepto", como varias veces tuve la oportunidad de platicarlo con él. Lo que quisiera añadir es que Ellacuria fue zubiriano teórico y zubiriano in actu, y que el realismo zubiriano se extiende al problema teologal: nuestro acceder a Dios es un acceder físico ${ }^{10}$, lo cual, en lenguaje menos técnico, lo hemos afirmado nosotros con estas palabras: "ve a Dios quien va a Dios". El problema teórico que expresa el Dios crucificado se decidirá en el caminar o no con él y hacia él.

\section{La fe de las víctimas. Aproximación histórica}

Vamos a reflexionar ahora sobre la fe de los creyentes en situaciones y procesos como el salvadoreño, sobre si y cómo se hace presente en esa fe el Dios crucificado, y sobre si y cómo esa fe es liberadora.

\subsection{En qué Dios creen las víctimas}

En lo sustancial es evidente que las víctimas creen y desean a un Dios liberador, y ahora además lo han introducido en su misma fe como algo central. En otras palabras - y esto es logro grande de la Iglesia de los pobres y de la teología de la liberación-, su fe teologal se dirige a un Dios de vida y liberador de las víctimas. Dicho en términos bíblicos, creen en el Dios que libera de la opresión de Egipto y en el que, en Jesús, anuncia la llegada de un reino contra toda opresión y como fin de toda desventura. Es éste un gran cambio en la visión de Dios que tienen los pobres, y es la primera novedad de su fe leologal después de siglos.

Se puede presuponer que ese cambio ya se ha dado cualitativamente, aunque nunca se pueda dar definitivamente por sentado", pero entonces es precisamente cuando surge la pregunta de si las víctimas ya concientizadas están abiertas 
siquiera a la noción de un Dios crucificado, qué significa para ellas ese Dios y si su aceptación es algo liberador o un peligro de recaída en la alienación religiosa.

Desde mi experiencia en El Salvador he de decir -resumiendo- que entre las mayorlas populares (a) Dios sigue teniendo primacía absoluta como algo último, (b) que en medio de la opresión han descubierto la dimensión liberadora de ese Dios, (c) que a veces les surge la duda -que puede llegar hasta la protesta, como en la teodicea clásica- sobre ese Dios, y d) por último, que también en el Dios crucificado encuentran liberación. Digámoslo primero en sus propias palabras, pero con una advertencia previa.

Al lector occidental hay que hacerle notar que los pobres no son dados a formular protestas contra Dios tal como ocurre -o solía ocurrir en occidente antes de la postmodernidad-, sino que hasta salen en su defensa cuando Dios es "atacado". Así, por ejemplo, cuando un periodista, agnóstico, de un país europeo preguntó a un campesino de Chalatenango -con respeto, eso sicómo podfa creer en Dios si él, su familia y su pueblo habían sufrido tantas atrocidades, el campesino le contestó con naturalidad y con el mismo respeto: "Usted no entiende. Dios nos dio ia cabeza para pensar, el corazón para amar y las manos para trabajar. El mal to hacemos nosotros, no Dios".

En conjunto, las víctimas no dudan, pues, de Dios, sino que agradecen y defienden a Dios, aun en aquellos momentos en que suele surgir con frecuencia la protesta de la teodicea. Un sacerdote de Morazán, zona muy sufrida por la represión y la guerra, se pregunta cómo es esto posible cuando el pueblo ha pasado por todo, bombardeos, asesinatos, masacres... Sin embargo, la gente le contesta: "Ayer tuvimos un bombardeo y nos salvamos por Dios... Dios actúa, Padre... Dios está con nosotros, Padre, porque si no hubiera estado Dios, hubiera sido aún peor"'2.

A veces, sin embargo, las cosas no son así. El mismo sacerdote de Morazán se hace la siguiente reflexión después de la masacre de El Mozote.

Más de mil campesinos asesinados. No exagero. Yo vi muchos de los cadáveres mutilados, deshaciéndose. Días después se sentía aún un olor insoportable. Las casas destruidas, todos muertos... En aquel pueblito que para mí era la alegría, eran mujeres y niños, esos niños que nunca vemos en la montaña jugando... El Mozote, un caserío tan alegre, con tanta vida... Cuando miré las pilas de los muertos, la destrucción, no pude aguantar. ¿Cómo es posible que precisamente aqul, a donde he llegado tantas veces para decir que Dios es un Dios cercano y que nos quiere, que no queda indiferente ante el dolor, que precisamente aquí suceda una masacre tan espantosa? ${ }^{13}$. 
Y no sólo el sacerdote europeo que ha pasado por la ilustración, sino también los campesinos se hacen la misma pregunta.

Cúntas veces no decimos que Dios actúa en nuestra historia... Pero, Padre, y si actúa, ¿cuándo acaba esto? ¿Y tantos años de guerra y tantos miles de muertos? ¿Qué pasa con Dios?'4.

Por último, a veces acaece una difícil síntesis, en la realidad más que en el concepto, por supuesto. Ese Dios a quien creen liberador por ser Dios de la vida, misteriosamente, escondidamente, puede también traer esperanza cuando él mismo aparece sujeto al sufrimiento, cuando se muestra como un Dios crucificado. Los campesinos no usan esa conceptualidad, por supuesto, pero a mi entender lo hacen en lenguaje y conceptos equivalentes, cuyo peso, por cierto, es mayor que el de nuestra conceptualidad. No se les ocurrirá usar formulaciones como la de "un Dios crucificado", pero se gozan en un Dios cercano y comprenden bien que en la cruz de Jesús y en las actuales cruces de los mártires hay algo de salvación para ellos.

$Y$ eso ocurre no s6lo porque creen que la cruz lleva a la resurrección - lo cual, en general, aceptan como cristianos y lo esperan históricamente en sus trabajos y luchas-, sino porque la cruz, en sf́ misma, dice ya cercanía a su propia realidad. Y como ellos, además de pobres y oprimidos, son los distanciados y marginados, todo lo que sea cercanía ya lleva consigo algo de salvación. Como cristianos, eso lo expresarán más con referencia a Cristo crucificado que en el lenguaje de un Dios crucificado. Pero están alirmando, en cualquier caso, que la "cercanía teologal" es buena.

\subsection{Qué ven de liberacion en un Dios crucificado}

Para introducirnos en la respuesta a esta pregunta podemos -en forma grafica- comenzar preguntándonos qué Dios interesa al pueblo crucificado, el del Exodo o el de la cruz. La respuesta no es sencilla, sino que es compleja y diferenciada. Para hacerla comprensible usaremos las categorlas de alteridad y de afinidad, y desde ahí podremos preguntarnos qué de Dios atrae a los pobres: su alteridad y/o su afinidad. Una vez más, los pobres no utilizan esos conceptos, pero quizás en base a analoglas históricas, es decir, en base a cómo ven a personas no-pobres, y qué ven en ellas de salvifico para elios, algo podemos barruntar de lo que piensan de Dios, el radicalmente otro.

Es una experiencia histórica repetida en El Salvador que muchos no-pobres se han acercado a los pobres, asI un Monseñor Romero, un Ignacio Ellacuría y muchos otros, sacerdotes, religiosas, profesionales... Desde una perspectiva sociológica, todas estas personas expresan alteridad con respecto a los pobres y éstos ven posibilidad de salvación precisamente en esa alteridad, es decir, tienen 
la experiencia de que la alteridad no tiene por qué ser necesariamente opresora o ser simple diferencia económica, política, militar, con respecto a ellos, sino que puede ser capacidad de servicio y, por ello, capacidad de traer salvación. Si se les pregunta a los pobres, por tanto, si prefieren a un Monseñor Romero sin alteridad, viviendo como uno de ellos en penuria, indefensión, incapacidad de defenderlos, los pobres responderán que no. Dicho en palabras gráficas, si en El Salvador hay cuatro millones de pobres, éstos no tienen ningún interés en que aumente en uno más su número. Su interés consiste más bien en que la alteridad pueda ser servicio y sea, así, salvación.

Esto, sin embargo, no es toda la verdad. Es un hecho también que cuando las personas que se les acercan con su alteridad participan de alguna manera en su destino (hostigamiento, difamación, persecución, indefensión, asesinato...), es decir, cuando junto a la alteridad se da algún tipo de afinidad, los pobres de este mundo sienten que algo bueno les ha ocurrido. En otras palabras, la afinidad con la realidad de ellos es también salvífica y aun liberadora, aunque en forma distinta a la salvación que puede producir la alteridad, salvación eficaz por poderosa. Así, cuando no-pobres con prestigio y poder han participado hasta el martirio en los sufrimientos de los pobres, éstos han sentido -en medio de lágrimas y protestas- algo positivo, algo salvílico.

Desde una perspectiva del no-pobre, distinta por lo tanto, pero convergente, así lo vio Monseñor Romero, y asf lo afirmó en palabras impresionantes hasta el día de hoy:

Me alegro, hermanos, de que nuestra Iglesia sea perseguida, precisamente por su opción preferencial por los pobres y por tratar de encarnarse en el interés de los pobres... Sería triste que en una patria donde se está asesinando tan horrorosamente no contáramos entre las víctimas también a los sacerdotes. Son el testimonio de una Iglesia encarnada en los problemas del pueblo ${ }^{15}$.

Monseñor Romero vio en la cruz algo positivo, no sólo por ser camino a la resurrección, sino por ser ya expresión de encarnación y de encarnación consecuente hasta el martirio, es decir, vio en la cruz afinidad y máxima afinidad con los pobres. Eso mismo parece ser lo que captan como positivo y salvífico las victimas de este mundo. $Y$ por eso, si tratamos de responder a la pregunta qué Dios prefieren las víctimas, si el del Exodo o el de la cruz, la respuesta es compleja y dialéctica.

Es claro que las victimas esperan un nuevo éxodo y al Dios que tiene poder para generarlo. Pero, aunque no sea evidente, es también real que las victimas algo de bueno encuentran en un Dios sujeto, él también, al sufrimiento que arrancan los capataces. La liberación total que proviene de Dios la experimen- 
tan, entonces, dialécticamente, de dos formas diferentes y complemantarias. Una, que es posiblitada por la alteridad de Dios, y otra, que es posibilitada por la afinidad. Lógicamente, la primera precede a la segunda, pero la segunda puede ser también real, y quedar unificada con la primera $Y$ por ello, la liberación que experimentan en un Dios crucificado no es ya sólo el consuelo que siempre han sentido ante el crucificado, sino un consuelo unido al deseo de y al trabajo por la liberación histórica.

Esta es nuestra interpretación de lo que ha ocurrido en los procesos de liberación. Lo que queremos añadir es que, en definitiva, eso es algo que sólo se puede constatar, y no extrapolar desde conceptos previos, y que por ello hemos insistido antes en el enfoque histórico y no meramente conceptual del terna.

\section{La liberación que trae un Dios crucificado. Aproximación teórica}

Lo dicho no es nada obvio, pero es real. En buena lógica bien pudiera ocurnir que las victimas razonasen de la siguiente manera: si ha de haber liberación, Dios no puede estar crucificado, y si hasta Dios está crucificado es que no hay posibilidad de liberación. En este caso, cruz en Dios y liberación de parte de Dios se excluirfan mutuamente. Pero también pudiera ocurrir que las victimas pensasen que un Dios absolutamente distinto y alejado de nosotros, sobre todo en lo más hondo nuestro, el sufrimiento, "tampoco sería de fiar".

Sobre este dilema queremos volver ahora en forma más teórica, notando que el problema existe desde el comienzo de la fe cristiana: cómo relacionar Dios y sufrimiento, qué hace Dios ante el sufrimiento de los seres humanos, y si y cómo le afecta ese sufrimiento a Dios. Ahora nos vamos a concentrar sólo en este último punto y sacar algunas consecuencias.

\subsection{Relación entre liberación y afinidad}

El problema es serio, evidentemente, pero es bueno recordar que no es nuevo y que de alguna forma ya se planteó en el primer concilio ecuménico de Nicea en el año 351. Recordemos muy brevemente que lo que estaba en juego en ese concilio era la divinidad del Hijo - del Hijo, no del Padre, pero divinidad a fin de cuentas- ante el rechazo de Arrio. El concilio condenó la posición de Arrio y definió la plena divinidad del Hijo, consustancial al Padre. Lo importante, sin embargo, es recordar la razón del rechazo de Artio: un logos divino no pudo estar en un Jesús de Nazaret limitado y sobre todo sufriente. Cristo, pues, no sólo no era Dios, sino que no podía ser Dios. Contra Arrio, el concilio proclamó la divinidad de Jesucristo - grandiosamente-, y, por así decirlo, elevó el misterio de Dios a misterio absoluto, reduplicativamente misterio: 


\begin{abstract}
A] poner en contacto los dos términos Dios-sufrimiento, el Concilio de Nicea nos sitúa ante las dos cuestiones más decisivas que se han dado en la historia y en la vida de los hombres. $Y$ al responder afimativamente que se da una cópula entre ambos, pone de relieve el nervio mismo de la fe cristiana, en todo lo que tiene de irrupción impensada e inesperada, que no encaja fácilmente en los esfuerzos explicativos ni en los deseos humanos y que más bien es juicio y condena de éstos ${ }^{16}$.
\end{abstract}

Se mantuvo, pues, y quedó confirmado el escándalo expresado ya en Pablo y Marcos, pero ello no sólo por mera fjdelidad formal a los textos del Nuevo Testamento, sino por una intuición que, en nuestra opinión, se mantiene hasta el día de hoy: sin afinidad no hay salvación. Y esa alinidad tiene que llegar a los más hondos niveles del ser humano, precisamente all donde la expectativa de salvación es más necesaria y, a la vez, parece más difícil de conseguirse: el sufrimiento ${ }^{17}$.

Esto puede decirse de muy diversas formas, y así la teología griega fraguo el axjoma "lo que no ha sido asumido no ha sido redimido" 18 , y la teología latina el de "sin derramamiento de sangre no hay salvación". En conceptualización modema y en lenguaje paradojico - pero que es paradojico por estar al servicio de una realidad paradojica-. Bonhoeffer decía que "sólo un Dios que sufre puede salvarnos", y Molımann dice en conceptualización hegeliana:

Sólo cuando toda calamidad, el abandono de Dios, la muerte absoluta, la maldición infinita de la condenación y el hundimiento en la nada está en Dios mismo, la comunión con ese Dios es salvación ${ }^{19}$.

En los dos últimos textos se afima que el sufrimiento le afecta a Dios, también en cuanto Padre, mientras que en los dos primeros se afirma que el sufrimiento afecta al Hijo, sin entrar en directo en la primera problemática. En la actualidad, la teología reacciona diversamente ante la posibilidad de que el sufrimiento le afecte a Dios Padre, que fungiría aquí como expresión de lo últimamente último del misterio. Así, mientras unos hablan de un Dios crucificado $^{20}$, refiriéndose también al Padre, otros quisieran distanciar al Padre comprensiblemente- de todo posible sufrimiento y por una razón precisa: para no elemizar la negatividad en Dios o, dicho en positivo, para que, al menos en Dios, pueda existir un reducto de pura positividad ${ }^{21}$.

En nuestra opinión, sin embargo, afirmar que el sufrimiento afecte tanto al Padre como al Hijo o sólo al Hijo no es lo decisivo, pues en cualquier caso se está introduciendo el sufrimiento en Dios —en el Hijo, la divinidad a modo de filiación-, y lo importante y aquello ante lo que hay que tomar postura perso- 
nal y existencialmente es la afinidad de Cristo con nosotros en el sufrimiento y muerte de cruz, si eso es o no salvifico.

Eso último hay que entenderlo bien. No se trata de recaídas en el dolorismo, ni en ignorar que la salvación proviene de la totalidad del misterio pascual muerte-resurrección, con mayor precisión todavía de la totalidad de la realidad de Jesús: misión-cruz-resurrección. De lo que se trata es de recalcar que el "momento" de cruz, aun con independencia lógica de la resurrección, es ya percibido como salvífico en cuanto expresa afinidad y honda afinidad con las victimas de este mundo.

\subsection{La salvación que trae Dios en cuanto crucificado}

Aun cuando se aceple en principio que en la afinidad hay salvación, no hay que suponer que eso se acepta y se mantiene quasi-mecánicamente. En palabras sencillas, siempre queda la pregunta, la sospecha y la duda sobre qué Cristo nos interesa, y especialmente qué Cristo interesa a las víctimas de este mundo, si el de Nicea o el de Arrio, si un Dios que se ve amenazado en su poder por el sufrimiento o un Dios todopoderoso, aunque transido de apata hacia los seres humanos. Pero aunque la pregunta siempre está viva, también sigue viva - pensamos- la intuición fundamental de la respuesta: sea lo que sea de Cristo y de Dios, la pura alteridad no humaniza, sin algún tipo de afinidad no hay salvación. Y queda entonces la tarea de mostrar 0 , al menos, de verbalizar, en qué consiste esa salvación.

\section{a) El hecho de la afinidad como salvación}

El que el sufrimiento le afecte a Dios expresa la superación del deísmo y de la apatheia de los dioses griegos, pero con ello se quiere decir algo más radical: en lenguaje doxológico, y por ello no ulteriormente analizable, se quiere expresar la posibilidad en Dios de mostrar solidaridad con la creatura que sufre, el poder ser un Dios-con-nosotros y un Dios-para-nosotros, aunque para ello Dios mismo se auto-determine a ser también, posiblemente, un Dios-a-merced-de-nosotros.

Qué de bueno haya, en concreto, en esta muestra de solidaridad, por definición no es cosa fácil de determinar y de poner en palabra por quienes son no-víctimas, y en último término se tratará de una realidad primigenia indeducible del puro concepto. Pero creemos que quizás pueda formularse de la siguiente manera: lo salvifico y liberador de un Dios crucificado está en la superación de la orfandad, de la soledad radical, de la indignidad total que experimentan los pobres y las víctimas de este mundo. El que Dios, el que aparentemente es la no-víctima por antonomasia, se acerque y participe en la condición y destino de las víctimas y el que eso ocurra por salvarlas, es visto como algo positivo y salvífico, $y$ algo que incluso confima y orienta sus luchas 
y trabajos, algo que da ánimo y esperanza - y algo que no es en nada paralizante ni alienante. En definitiva, hay experiencia de salvación porque hay experiencia de comunión, y de comunión con Dios. Y como toda comunión -y especialmente esa comunión- produce identidad, dignidad y gozo.

Ese Dios - sea cual fuere su poder- tiene credibilidad ante los pobres porque se ha acercado a ellos en lo que ellos tienen de víctimas, $y$ en ello sienten gozo. En mi opinión, en la experiencia de las víctimas, el Dios liberador expresa la eficacia de la salvación que desean y el Dios crucificado expresa la gracia y la ternura. Si la tradición para referirse al misterio de Dios ha usado la expresión del Deus maior, para referirnos al Dios crucificado bien podemos hablar del Deus minor, y ello puede ser una buena noticia. Un médico norteamericano que pasó varios años en El Salvador, postrado ahora con una grave enfermedad, lo ha expresado con estas palabras:

A lo largo del tiempo sentí el dolor de la vida colidiana de los pobres en las comunidades marginales y en el campo. Era en medio de este dolor que encontré algo de lo que buscaba -un Dios no sólo mayor, sino un Dios menor. Entre ustedes encontré a un Dios bueno y justo, que camina con su pueblo, y que todavía sufre al lado de los que sufren ${ }^{2}$.

\section{b) La salvación que trae un Dios en la cruz}

Además de esa salvación fundamental que olorga la afinidad de Dios con las víctimas, el hecho de que esa afinidad se muestre en y a través de la cruz - y no de otra realidad- expresa otras dimensiones de la salvacion. Por eso, siguiendo el modo de proceder de I. Ellacurfa al historizar la salvación que trae el pueblo crucificado ${ }^{23}$, veamos cuáles son $\longrightarrow$ parecen ser- para las víctimas los rasgos salvificos de un Dios crucificado. En otras palabras, concretemos esa salvación.

La tesis central es que, si Dios está en la cruz, ese hecho da ultimidad y radicalidad a lo que "de positivo" se muestre en ella, diviniza, por así decirlo, lo que haya de salvación histórica en la cruz y eleva a revelación de Dios la verdad historica que aparece en ella. En otras palabras, al hablar de las víctimas como siervo sufriente de Yahvé, estamos haciendo dos cosas. Una es divinizar la condicion sufriente del pueblo histórico, y la otra es historizar a Dios. De esa manera, lo que sea y diga el pueblo crucificado es sacramento de lo que es y dice Dios, y por ello lo que de salvación haya en el siervo es sacramento de la salvación que Dios ofrece al estar precisamente en la cruz.

Más en concreto, esto significa que así como el siervo de Yahvé es "luz de las gentes", así un Dios crucificado, en cuanto tal, es también luz y ofrece dos luminosas verdades para el creyente -que pueden ser comprendidas también análogamente por el no creyente, si piensa en lo que para él es la realidad 
última. La primera es una verdad teórica: lo transcendente se encarna en y asume lo histórico y todo lo histórico, y sin quitarle nada de entidad. Todo lo histórico se puede predicar de Dios (entendida aquf la divinidad desde el Hijo a la manera de filiación), incluido el sufrimiento, la cruz y la muerte, sin que -y esto es imporante- la inversa sea verdad ${ }^{24}$, es decir, sin quitar entidad a lo humano y a la historia. Y la segunda es una verdad práxica: para erradicar el pecado hay que cargar con él, lo cual se extiende al mismo Dios. Esto quiere decir que se debe luchar contra el pecado para alcanzar la liberación, como lo exige la modernidad, pero más allá de ella se afirma que hay que cargar con êl desde dentro, pues sólo luchando contra él desde fuera no se lo erradica. $Y$, por supuesto, se afimna contra la postmodernidad que no se debe banalizar el pecado y la lucha contra él. Todo esto es reconocido por Jos creyentes letrados y estudiados, y por los pobres y las víclimas como cosa buena.

También es salvífico que el Dios crucificado cuestiona nuestra visión de Dios, y que la nueva visión que surge de la superación de las antiguas no paraliza, sino que desencadena praxis, y no lleva a la resignación, sino a la esperanza. Esto es realmente notable y la argumentación en su favor sólo puede consistir en mostrar que así ocurre -0 deja de ocurrir. Pero reflexionando existencialmente y tratando de buscar reflexivamente un por qué a un hecho tan escandaloso y novedoso en comparación con lo que ocurre en otros lugares, la razón última parece estar en el amor que se expresa en la cruz.

Esto es lo que afimma el Nuevo Testamento ${ }^{25}, y$, en mi opinión, esto es también lo central que captan las víctimas. No se trata entonces sólo ni principalmente de que creyentes sencillos o jlustrados acepten la "bondad" de la cruz, como paso necesario para una resurrección tras la muerte, 0 , en términos históri$\cos$, que se acepten sufrimentos y muerte como paso necesario para un triunfo de la revolución. Si aś fuera, la cruz quedaría reducida a escándalo provisional, es decir, dejaŕa de ser radicalmente escándalo, pero perdería también su propia identidad y no mostraría nada específico positivo. Pero la cosa es más honda. Las cruces históricas, la cruz de Jesús y "el Dios crucificado" expresan en y a través de la cruz amor, y el amor -y en último término sólo el amor-es lo que sigue generando praxis, compromiso, esperanza, sentido, vida...

La cruz es, pues, símbolo de muchas cosas: de muerte, de pecado, de tragedia, pero es también símbolo del amor de Dios, que es lo que en último témino afirma el Nuevo Testamento. $Y$ ese amor es lo verdaderamente último, aunque tenga que expresarse en formas tan urágicas como la cruz de Jesús. En efecto, existiendo ya varios modelos teoricos supuestamente explicativos de cómo la cruz trae salvación, la teología de Pablo y la de Juan, en definitiva, relacionan la cruz de Jesús esencialmente con el amor de Dios, y con ello afirman que el amor tiene mayor ultimidad que la muerte. $Y$ eso es lo que expresa, en definitiva, un Dios crucificado: la muerte podra matar muchas cosas, pero no ha podido matar al amor. 
Que las argumentaciones del Nuevo Testamento y nuestras propias reflexiones "convenzan" o no es una cosa, pero lo que sí queda claro es que los creyentes vieron, desde el principio, expresado y actuante en la cruz el amor de Dios. Eso es salvifico -y eso es lo salvífico-, eso es lo que genera vida y da esperanza, pero no sólo quasi-mecánicamente como pudiera ser comprendida la secuencia muerte-resurrección (como comprende Platón la secuencia noche-día), sino como la palabra última de Dios y la palabra última de la realidad: donde hay amor hay esperanza y hay vida. El amor crucificado no es el todo del amor, ciertamente, pero si en la cruz hay realmente amor, entonces, no hay que sorprenderse de que también un Dios crucificado genere vida.

Después de convivir algunos años con los pobres y las víctimas de El Salvador, una religiosa norteamericana, recientemente fallecida, escribio estas palabras:

Mis reflexiones son sombrías, hasta dolorosas a veces. Viendo las caras, escuchando las historias, mi corazón no puede dejar de doler. Pero no estoy triste... Me encuentro aprendiendo de esa gente lo que siempre habla esperado que fuera verdad: que el amor es más fuerte que la muerte ${ }^{26}$.

Quizás esta palabra exprese la salvación más específica que trae un Dios crucificado. Si en la cruz, en la muerte, está presente el mismo Dios, entonces es que - contra toda apariencia- Dios, la vida, el amor, tienen la última palabra.

\section{Qué hace posible la fe en un Dios crucificado}

Hemos dicho que a las victimas también "les gusta" la cercanía, la afinidad de Dios - hasta la cruz-, y que de ello pueden sacar vida y esperanza. Hemos dicho también que los creyentes ilustrados pueden comprender lo positivo de un Dios en la cruz como radicalización de lo que en la cruz hay de luz y de amor. Sin embargo es obvio que la fe en un Dios crucificado es todo menos evidente y por ello queremos preguntamos - más allá de repetir que la fe es un don-qué realidades parecen hacer posible o verosimil tan escandalosa afirmación. Más en concreto, nos preguntamos qué tipo de fe puede encontrar a Dios y a un Dios crucificado en medio de procesos populares, tan dolorosos y trágicos. Y para ello volvemos a ver lo que parece ocurrir en la realidad: esa fe surge de la praxis del amor y es llevada por la fe de otros.

\subsection{La fe que cuestiona a Dios}

Ya queda dicho que no es evidente que surja y se mantenga la fe en Dios en los procesos de liberación por lo que éstos tienen de sufrimiento, dolor, escándalo, fracaso, desencanto... Por ello, antes de analizar la fe concreta en esos proce- 
sos, vamos a fijarnos en algunas reacciones tIpicas de cómo los seres humanos se ponen delante de Dios en los momentos de oscuridad. Es cierto que tanto si estamos en una situación de esperanza de éxodo como de escándalo de cruz ${ }^{27}$, nuestra expectativa es siempre que Dios sea bueno para nosotros. Pero cuando lo hacemos $-y$ nos enfrentamos con él- en medio de la negatividad y sinsentido de la existencia, la expectativa está llena de zozobra, oscuridad, sospecha, protesta y miedo.

La Biblia da testimonio, con toda claridad y sin ningún rubor, de muchas situaciones de oscuridad y sin sentido en que se encuentra el ser humano. En esas situaciones, éste pregunta y aun cuestiona a Dios, y Dios tiene, por así decirlo, que justificarse ante aquél. Así, en el Antiguo Testamento, Jeremías se queja a Dios, y Job y Qohelet cuestionan a Dios. En el Nuevo Testamento Jesús lanza el grito que se ha convertido en símbolo de toda teodicea: "Dios mío, Dios mío, ¿por qué me has abandonado?".

Quienes cuestionan a Dios en estos casos son creyentes y, en definitiva, aceptan a Dios - aun sin comprenderlo-, con lo cual lo aceptan in actu como misterio, le dejan ser Dios y así también pueden aprehenderlo como Dios. En lo que queremos insistir, sin embargo, es en que Dios aparece aqul como el preguntado y el cuestionado por los seres humanos y el que tiene que dar una respuesta. Lo que está en juego, entonces, es la realidad de Dios, y desde esa perspectiva el que Dios mismo esté en la cruz sin pronunciar palabra, puede ser interpretado diversamente como "silencio-respuesta" a una pregunta para lo que no hay respuesta, sino sólo silencio, o como "decepción, desencanto y frustración" para el ser humano o como reconocimiento de que la fe en Dios es una "vana ilusión", o, por así decirlo, como la aceptación por parte de Dios no ya de no querer, sino de "no poder dar una respuesta"2".

En la Escritura, sin embargo, la problemática de la fe en Dios y del sentido último de la vida aparece también desde otra perspectiva. Según ésta, no es ya el hombre el que se pone delante de Dios y lo cuestiona, sino que él es el preguntado y el exigido por Dios. Esto es cosa bien sabida, pero la recordamos no simplemente para salir por los fueros de Dios, como lo hacía la teologla dialéctica, K. Barth sobre todo, insistiendo en "la infinita distancia entre Dios y las creaturas", sino para mostrar el otro polo de la relación Dios-hombre, que puede ayudarmos a comprender cómo es posible la fe en un Dios crucificado.

Volviendo a los ejemplos anteriores, Jeremías, Job, Qohelet y Jesús pregunLan para saber, y para que, al menos desde Dios, las cosas, la realidad, la vida en definitiva sengan sentido. Que la respuesta de Dios "convenza o no", por así decirlo, es una cosa, pero lo que queremos recalcar es que se espera al menos una palabra iluminadora, la respuesta a un por qué: que el ser humano sepa desde Dios, al menos, por qué son aśl las cosas, qué sentido hay tras el aparente o evidente sinsentido, qué solución hay, en esta o en otra vida, a la miseria de la 
condición humana y a la injusticia de la historia. Pues bien, en momentos cumbres, Dios contesta, y contesta como Dios, y por ello, lo hace trayendo consigo la infinita distancia entre creador y crealura ${ }^{20}$.

\subsection{La fe que surge de la praxis del amor}

Otras veces, sin embargo, no es así. No es el ser humano el que se dirige y cuestiona a Dios, sino que es Dios el que se dirige y exige al ser humano. Y, además, lo que exige al ser humano no es en directo una palabra o confesión, todo lo ortodoxa que se quiera, sino que le exige con ultimidad una praxis. Y lo que ocurre entonces, por lo que toca a nuestro tema, es que dentro de esa praxis, el ser humano puede seguir preguntando por Dios, sf, pero puede reformular y cambiar el sentido de la pregunta, y puede escuchar --dentro de la praxis- una novedosa respuesta.

Por ceñirnos a los evangelios sinópticos, en todos ellos aparece cómo Dios -a través de Jesús- se dirige a las creaturas y les exige con ulumidad una praxis. $Y$ en el cumplimiento de esa praxis se juega no sólo la dimensión ética y salvifica del ser humano, sino también una nueva epistemología para acceder y encontrar a Dios -que es lo que ahora nos interesa recalcar. Veámolo brevemente.

En Lucas eso aparece en la parábola del buen samaritano (Lc 10, 25-37). Las preguntas "qué he de hacer para ganar la vida eterna", "quién es mi projimo" son preguntas últimas que hace el ser humano, pero que en realidad son las preguntas últimas que a el se le hacen. Pues bien, la respuesta no es teórica, sino práxica, y es una respuesta que expresa una exigencia última, específica de Dios: hay que sanar a la víctima y por la única razón de que el sufrimiento está ahí y se ha interiorizado en lo más hondo de uno (moverse a misericordia, revolverse las entrañas = esplaginizomai). Qué palabra se le dirige al ser humano está dicho - lapidariamente- al final: "Vete y haz tú lo mismo".

En Mateo aparece ese mismo tipo de ultimidad en la parábola del juicio final (Mi 25, 31-46). Salvación y condenación eternas se deciden en una praxis concreta: la misericordia hacia los que están en necesidad. Asoma además aquí el problema epistemológico: ¿y qué del conocer a Dios? La respuesta es conocida: en la praxis del amor hay un acceso a Dios, el más definitivo, por afinidad real con lo que es el mismo Dios, independientemente de la conceptualización categorial que se haga de Dios. Así se cumple la otra exigencia globalizante de Jesús que menciona Mateo: "Sean buenos del todo, como es bueno el Padre celestial" (Mt 5, 48). En la relación con Dios - y desde Dios- es clara la prioridad del hacer sobre el puro conocer.

En Marcos, por último, vuelve a aparecer la ultimidad de la exigencia que se le dirige al ser humano. En el pasaje de Cesarea de Filipo -en una densa compo- 
sición teologica (Mc 8, 27-9, 8) - no son los hombres quienes preguntan a Jesús, sino que ellos son los preguntados por Jesús: "Y ustedes, ¿quién dicen que soy yo?". La pericopa y su secuencia son conocidas: respuesta (formalmente correcla) de Pedro, palabras de Jesús sobre su pasión, total incomprensión de Pedro, dura respuesta de Jesús e invitación-exigencia a seguirlo cargando con la cruz: "sígueme". Aquí no sólo se menciona la praxis como la dimensión en que se decide la realización cabal de lo humano en este mundo y su salvación transcendente, sino que el seguimiento se convierte también en posibilidad epistemológica: pasar del falso al verdadero conocimiento de quién es Jesús sólo es posible, al parecer, en el seguimiento. Quién es Cristo se va a saber desde dentro del seguimiento, y desde el seguimiento se podrá confesar o negar su realidad transcendente. En nuestra interpretación sistemática, desde el seguimiento se podrá tener la convicción de que —siguiendo a Jesús-- se hace más y mejor historia, de modo que ese "más" histórico funja como mediación del "más" transcendente. Y a la inversa, el máximo cuestionamiento de la fe en Cristo podrá provenir de la experiencia de que la praxis del seguimiento no abre, sino que cierra historia.

Esta exigencia a una práctica para conocer a Dios es una constante en la revelación, lo cual pudiera preverse ya a priori por dos razones, sobre todo si se trata de conocer a un Dios crucificado. La primera razón es que si Dios en cuanto total es el misterio último y globalizante de la realidad, nuestro acceso a él debe presuponer su radical alteridad, y, por ello, el intento de acceso debe ser lo más globalizante posible para encaminamos a ese misterio -aunque sea de forma humildemente asintótica- a través de todas las dimensiones de lo humano: lo cognoscitivo, lo esperanzado, lo celebrativo, lo práxico... Y la segunda razón es que, aunque se trata del misterio de Dios, algo de afinidad tiene que haber entre el ser humano que accede a Dios y el Dios accedido. Esa afinidad se deberá realizar en aquello que sea central en Dios y que lo haga ser formalmente Dios. Según la fe cristiana, esa realidad es el amor, historizado diversamente en la revelación como práctica de la misericordia, justicia, ternura..., pero amor a fin de cuentas.

Nada de esto garantiza, por supuesto, aceptar a Dios y menos a un Dios crucificado. Pero si queremos insistir en lo siguiente: no es lo mismo preguntarse por Dios desde la sola dimensión cognoscitiva que desde la dimensión práxica -añadida a aquélla. No es lo mismo buscar a Dios sólo con la inteligencia, que con la totalidad del ser humano. No es lo mismo verificar.la verdad de Dios según explique o no la historia, que según anime o no a hacer más y mejor historia.

\subsection{El Dios crucificado que acompaña a su pueblo}

Volvamos a la historia de El Salvador. Las mayorfas todavfa masivamente 
religiosas siguen aceptando a Dios con toda naturalidad, pero la situación de los creyentes comprometidos es más compleja. Estos creyentes que trabajan y luchan por la liberación no tienen por qué hacerse las reflexiones anteriores, y ya hemos dicho que desean un "Dios liberador" y que no usan el lenguaje del "Dios crucificado". Lo importante es recalcar que si llegan a hacerse, explíciu o implícitamente, la pregunta por Dios lo hacen desde una praxis. No es sólo por costumbre o mera curiosidad, no es movidos por la admiración aristotélica y ni siquiera por el sufrimiento que precede al pensamiento (Feuerbach), no es sólo desde la protesta para conservar al menos la dignidad. La gran diferencia es que si se preguntan por Dios lo hacen desde dentro de una práctica del amor.

Cuestionar a Dios es, pues, posible - lo han hecho santos y profetas-, puede ser bueno y, dado lo que somos los humanos, es prácticamente necesario. Pero no es la única posiblidad al ponernos ante el misterio. Y esa nueva posibilidad se da, en mi opinión, dentro de la práclica del amor. En ella, se podrá ofr una respuesta, la fe podrá encontrar a Dios en la historia, y a un Dios que, crucificado él mismo, acompaña a su pueblo en los momentos más trágicos. La fe puede encontrar a un Dios crucificado y salvador, y que es salvador también en cuanto está crucificado. Pero esa fe es una fe transida de praxis del amor. Este amor es el que en definitiva genera —o puede generar- esperanza, y este amor es el que posibilita $\longrightarrow$ puede posibililtar- $\mathrm{fe}$.

Los pobres, las victimas, no usan este lenguaje, por supuesto, pero hay en ellos un convencimiento hondo de que Dios está con ellos, a pesar de todo. Se podrá aducir su religiosidad popular para explicar el fenómeno, pero no se debiera pensar principitada y mono-causalmente que esa religiosisdad explica satisfactoriamente lo que es difícilmente comprensible para otros. Tras esa fe está un gran amor. Asf hablaban, en 1987, unos cristianos de las comunidades de oriente de El Salvador, abandonados, por cierto, por su obispo:

Nosotros somos unas comunidades abandonadas por nuestra diócesis. Nunca ha habido preocupación por nosotros. De lo que sí estamos claros es que Dios no nos ha abandonado ni nos abandonará jamás. Pues hemos podido experimentar su cercanía y su acompañamiento en los momentos más duros que hemos vivido a lo largo de esta guerra, donde lo único que se nos ha ofrecido ha sido la muerte. El nos ha ofrecido y dado la vida ${ }^{30}$.

\subsection{Los testigos de la fe en un Dios crucificado}

Para terminar este apartado digamos una muy breve palabra sobre el "llevarse mutuamente unos a otros en la fe". Si esa disponibilidad a dejarse llevar por otros en nuestra propia fe y a llevar a otros con nuestra propia fe le pertenece a la esencia de toda fe cristiana, con más razón se podrá hablar de su necesidad 
cuando se trata de la fe en un Dios crucificado.

No podemos alargarnos ahora en este punto ${ }^{31}$, pero recordemos - a modo de ejemplo importante- cómo la fe de los "sencillos", las miles de víctimas del pueblo salvadoreño, se vela posibilitada y confortada por la fe en Dios de Monseñor Romero. Y a la inversa, cómo la fe de Monseñor se vefa también animada por la de su pueblo. Y quisiera añadir, como recuerdo personal, cómo la fe en Dios de un Ignacio Ellacurfa - "ilustrado", nada crédulo- era también llevada por la fe de los sencillos y la de Monseñor Romero ${ }^{32}$.

En lo que queremos insistir es, pues, en que, por una parte, la fe liene una dimensión personal, indelegable, de soledad ante el misterio de Dios. Pero, por otra, también tiene la dimensión relacional hacia la fe de otros. En esa dialectica de soledad-comunidad se va haciendo la fe de las personas, y esa dialéctica es más necesaria cuando se trata de una fe escandalosa, la fe en un Dios crucificado.

Cuando el autor de la Carta a los Hebreos quiere animar la fe de unos creyentes cansados y desesperanzados pone ante sus ojos a "los testigos" de la fe. Y termina con el testigo por antonomasia, Jesús. Pero, además, presenta a un Jesús que también tuvo que ponerse ante Dios en oscuridad, con lágrimas y clamores, ruegos y súplicas. Y concluye: "Levantemos la mirada hacia Jesús del cual proviene nuestra fe" $(12,2)$.

Comenzábamos este apartado preguntándonos qué parece hacer posible la fe en un Dios crucificado. Nuestra respuesta, más como mystagogía que como doctrina, es doble: una fe dentro de una práctica del amor y una fe abierta a los testigos que creen en el Dios crucificado.

\section{La fe cristiana: "una religión del caminar"}

Muchos creyentes a pesar de todo siguen trabajando y luchando, les sigue impactando el Dios de vida y -aunque pasen por el trance de cuestionar a Dios- siguen caminando y creyendo. De esta forma están desarrollando un tipo de fe que responde in actu a lo que dice el mismo Dios a través del profeta Miqueas en un texto que muchas veces he citado:

Ya se te ha declarado, oh hombre, lo que es bueno y lo que el Señor espera de ti: practicar la justicia, amar con ternura y caminar humildemente con tu Dios (Miq 6, 8).

Este es el modo de ser y creer que, en mi opinión, expresa lo que ocurre en los procesos de liberación. No es que desaparezca la indignación de Jeremfas, la pregunta de Job o el escepticismo de Qohelet, pero estas preguntas se suelen hacer de hecho en un contexto más abarcador que el de la pura pregunta y 
cuestionamiento de Dios. Ese contexto, como queda dicho, es la praxis, que en el texto de Miqueas queda especificada en su contenido fundamental y en su dimensión teologal. La diferencia, por lo tanto, con otras formas de preguntarse por Dios y aun de cuestionar a Dios está en que la pregunta y el cuestionamiento se hacen desde dentro de una práclica, como hemos dicho.

\subsection{Caminar en liberación y humanización}

De dónde provenga esa opción primigenia por la praxis, es cosa a analizar cuidadosamente. Proviene, indudablemente, del hecho primario de querer vivir, pero no simplemente de una querencia cuyo objeto estaría asegurado en lo fundamental: la vida, sino de una querencia gravemente dificullada y amenazada por la muerte. Aquí está, indudablemente, la raíz más honda de la praxis.

Pero además, y en un contexto leologal, hay praxis porque en ella misma se experimenta vida. La praxis (de la liberación) no sólo está dirigida a conseguir la vida en sus dimensiones fundamentales, económicas y sociales, sino que ella misma es ejercicio de otras dimensiones fundamentales de la vida humana: la verdad, con su búsqueda, análisis, proclamación y denuncia profética; la misericordia, con su historización como justicia, defensa de los derechos humanos, temura; la esperanza, con su utopía; la celebración, con su gozo... En la praxis de liberación van apareciendo, pues, las diversas dimensiones de lo humano de modo que con todas ellas se va expresando la totalidad de lo humano y, dentro de esa totalidad, surge la pregunta por Dios y la posible respuesta de Dios.

Dicho de otra forma, y en el lenguaje de la tríada paulina, en los procesos de liberación aparecen ciertamente la esperanza y la caridad, y desde ellas se hace la pregunta por la $f e$. Dicho en lenguaje trinitario, en los procesos de liberación se da un seguimiento real del Hijo y hay experiencia de la fuerza del Espíritu, y desde ambas cosas -desde esa deiformación del ser humano, en lenguaje zubiriano- se hace la pregunta por el misterio último del Padre.

No afirmamos con esto que la fe en el misterio último de Dios-Padre se desprende mecánicamente de lo anterior, pero sf queremos asentar dos cosas. La primera es que la fe en el misterio último de Dios acaece de hecho -muchas veces juntamente con el seguimiento de Jesús y con la fuerza del Espíritu. Es pues - si es que llega a ser- una fe real y no sólo nominalmente trinitaria y totalizante en cuanto a su objeto. $\mathrm{Y}$ es una fe realmente humana y totalizante en cuanto al sujeto, pues acaece dentro de la totalidad de lo humano. $Y$ la segunda cosa es que esa fe en el misterio de Dios, aun en medio de la tragedia humana y del cuestionamiento de Dios, ocurre realmente, es algo real, y por ello liene sentido hablar de Dios y de un Dios crucificado.

En nuestra opinión no podemos avanzar más en dar razón de la fe en Dios. Puesto en términos teóricos, diríamos que más que verificar la verdad de Dios 
desde su capacidad de explicar el todo (W. Pannenberg), la verificamos desde su capacidad de transformar y humanizar -paulatinamente, humildemente- el todo. Ese misterio último, que llamamos Dios, ese Dios crucificado, solidario, viene -además- la capacidad de movernos para mover la historia. Lo que añade y en lo que insiste la cita de Miqueas es en que eso hay que hacerlo siempre, sin detenerse nunca en el camino.

\subsection{Y caminar con bumildemente con Dios}

Volviendo a la cita de Miqueas -en una interpretación libre, no exegética-, ésta nos ofrece y exige lo fundamental de ese caminar: practicar la justicia, es decir, trabajar para que en nuestro mundo llegue a ser real la familia humana, realidad masiva, diferenciada, conflictiva, utópica... y amar con ternura, es decir, relacionarnos con las personas concretas que le salen a uno al encuentro en la vida, con total respeto y apertura hacia ellas y también con la radical esperanza de que ellas pueden ser salvación para nosotros.

Este es lo que ofrece y exige Miqueas - con una claridad y sencillez que todo ser humano puede entender- para que el caminar sea humano. Pero además, a través de ello nos eleva a lo teologal. Viviendo así, se camina con Dios, ese caminar, en cuanto caminar con Dios, es cualificado con el adverbio "humildemente", tanto porque objetivamente nuestra praxis siempre será pequeña y limitada, en comparación con la divina, como porque subjetivamente el carninar es con Dios y por ello va siempre envuelto en el misterio, con lo que tiene de oscuridad o de exceso de luminosidad.

Lo que queremos recalcar, en cualquier caso, es que en la cita de Miqueas hay dos cosas sobre las que hay que tomar postura. Una es sobre la justicia y la ternura, y decidir si - sea cual fuere la realidad de la transcendencia- ahí se juega y se realiza lo humano. La segunda es sobre Dios, y decidir si la vida de los hombres es realmente un caminar con Dios. La respuesta a estas dos preguntas -no sólo a una de ellas- depende del ser humano. Ambas son respuestas en fe, aunque de diferente forma, y eso es lo que, en cualquier caso, afirma el cristianismo. Lo que la reflexión y la teología pueden añadir es que ambas cosas se remiten muluamente la una a la otra: que la "oscuridad" del caminar vive de la intrínseca "luminosidad" de la práctica de la justicia y de la ternura. Y que la "radicalidad" última con la que hay que hacer ambas cosas —más allá de la cual no se puede ir - vive de que el caminar es "con Dios".

Desde esta perspectiva quisiéramos caracterizar la fe cristiana como una religión o una fe del caminar. Lo que nuestra fe nos dice y exige, aquello a lo que nos invita y para lo que nos da fuerza es, ante todo, para caminar en la historia y para caminar de manera realmente humana. El cristianismo hace afirmaciones históricas y transcendentes, pero éstas últimas pueden y tienen que ser compren- 
didas a partir de aquéllas - lo cual, aunque obvio, hay que recalcar. De ahí también que el tipo de saber implicado en unas y otras es distinto. Sabemos de distinta manera lo que es el seguimiento del Jesús histórico que lo que es su realidad transcendente, de modo que el Jesús histórico es el que conduce a la alimación doxológica del Cristo de la fe. Pues bien, eso que decimos de Jesucristo podemos decirlo del cristianismo en su totalidad.

Digámoslo primero f́nomenológicamente. En el caminar real aparece -0 puede aparecer- la utopía que atrae con ultimidad y que mueve con radicalidad a pesar de que la historia la hace improbable y difícil muchas veces, y a pesar de que ouras veces no sólo no se avanza hacia la utopía, sino que se retrocede. Sin embargo, esa utopía que todavía no es está ahí haciendo que las cosas sean. Y en el caminar real aparece también $\longrightarrow$ puede aparecer- que con anterioridad e independencia de nosotros se nos ha dicho y se nos ha introducido en una tradición — metafísica - del hacer la bondad y el bien, de ser y sabernos ya acogidos y aun amados, antes e independientemente de nuestra praxis. Ese "antes", invisible, que no nos ha pedido permiso para ser y para orientarnos, impulsa la dirección de las cosas y nos orienta a nosotros. Y esa orientación es primigeniamente buena. Fenomenológicamente queremos decir, pues, que en la práclica de los procesos de liberación se "experimenta" el futuro que atrae y el origen que impele, ambas cosas con radicalidad y ultimidad, y ambas cosas experimentadas como posibilidad de bendición y salvación.

Si y cómo se formule esto teológicamente, más aún, teologalmente, es el misterio último del ser humano. Los cristianos mencionan a Jesús, el Hijo, como norma fundamental, historizable por supuesto, para caminar en la historia. Mencionan al Espíritu, interiorizado en personas y pueblos como luz y fuerza, para hacer real - no sólo pensado- ese caminar. Y a eso añaden que en ese caminar se hace ya presente "humildemente" el misterio último —el Padre. Según esto, los seres humanos caminamos según Jesús y con la fuerza de su espíritu, pero caminamos también con Dios. Desde esa experiencia podemos afirmar que provenimos de Dios - el de la creación, la protologla - y que caminamos hacia Dios- el de la utopía, la escatología. El caminar no es, pues, deambular: es provenir de y es acceder a. Lo importante que aporta el cristianismo es la calidad del caminar. De ahí crece $\longrightarrow$ puede crecer- la convicción de que provenimos de una bondad original y accedemos a una plenitud final.

Lo que queremos decir es que "de lo que más sabe" la fe cristiana es del caminar en la historia, y ello no sólo por razones epistemológicas generales, sino por el contenido fundamental de esa fe: eso es lo que hizo Jesús, caminar en la historia según el corazón de Dios y mostrando así —en él- la realidad de ese Dios. Desde ese "gran saber" sobre la historia, la lógica de la fe habla sobre el origen y sobre el final, y sobre la gracia que lo pernea todo, que actúa antes que todo y que está más allá de todo ${ }^{33}$. 
Para terminar quisiera hacer unas reflexiones muy breves, dirigidas sobre todo al lector del primer mundo. Unas versan sobre lo dicho acerca de Dios y otras sobre lo dicho acerca del caminar.

La primera es que en la tradicción occidental, como ya hemos dicho, el problema teologal y la teodicea se ha expresado como cuestionamiento de Dios, y el problema de los creyentes ha consistido en encontrar luz en la oscuridad, certeza en la duda, etc. En los procesos de liberación, sin embargo, se hace muy presente también y con gran fuerza el problema del ser humano y de la antropodicea, lo cual tiene también su equivalente en lenguaje religioso: los ¡dolos. Y entonces el problema no es sólo encontrar luz, sino sacar fuerza, firmeza y amor para defender a las víctimas y combatir a los ídolos. En otras palabras, se podrá o no aceptar a Dios, pero hay que estar muy claros en la activa existencia de los ídolos. Y se podrá o no aceptar a un Dios crucificado, pero hay que estar muy claros en la existencia de ídolos crucificadores.

La segunda es que — desde el Dios crucificado- hay que complementar la intuición de nuestro acceder a Dios con la del acceder de Dios a nosotros. Y más en concreto, la de acceder a un mundo crucificante para ser solidario con un pueblo crucificado. Lo que el Dios crucificado añade a Dios es su solidaridad con las víctimas de este mundo.

La tercera es que "el caminante no hay camino, se hace camino al andar", hondo, existencial, siempre cuestionante y siempre animante, se reformula en los procesos de liberación en la línea de Miqueas, como lo ha hecho don Pedro Casaldáliga:

Camino que uno es

que uno hace al andar.

Para que otros caminantes

puedan el camino hallar.

Para que los atascados

se puedan reanimar.

Para que los ya perdidos

nos puedan reencontrar ${ }^{34}$.

En otras palabras, se trata de des-centrar el propio caminar: "haz del canto de tu Pueblo el rilmo de tu marchar"35. Y ese caminar des-centrado, el exigido por Miqueas, es el que permite el que pueda ser creído como un caminar con Dios.

Por último, si alguien sigue insistiendo y preguntando por qué hablar de caminar con Dios y más aún con un Dios crucificado, por qué hablar siquiera de un caminar y más aún de un caminar des-centrado, por qué no contentarnos con 
el carpe diem, aceptar el vanitas vanitatum, explotar honradamente con el maldito el día en que nací... cualquier respuesta que se dé es fe. Lo que hemos querido decir es que en los pueblos crucificados y sus procesos de liberación existe esa fe en Dios -fe razonable, como exigen unos, fe vivificante, como hemos añadido nosotros.

Se puede o no creer en Dios, pero si existe fe es evidente que tiene que estar transida de dialéctica entre luz y oscuridad, entre historia y transcendencia, entre caminar y meta final. Si la fe en Dios es además fe en un Dios crucificado esa dialéctica se hace más necesaria: en la historia creemos, a la vez, en el Dios de la liberación y en el Dios de la cruz, pero al final no puede haber crucifixión.

Estas reflexiones - pensamos - se imponen a todo creyente, y se formulan en el lenguaje más sofisticado de ilustrados o en el más directo de los sencillos. Lo que personalmente queremos decir desde nuestra experiencia en El Salvador es que cuando todo ha sido razonado, disculido, rebatido y argumentado, hay quienes dicen que el caminar de Miqueas con la misericordia y fidelidad de Jesús es lo que mejor pone en palabra lo que ellos mismos experimentan en su caminar - que no deambular-, es lo que mantiene, aun con muchos problemas y en contra de muchas dudas, sentido y esperanza en sus vidas, es lo que exige e invita a una vida en el amor. Y entonces, se ven forzados también a poner en palabra, sin ningún triunfalismo ni prepotencia, pero sí con honradez, agradecimiento y gozo, que caminan humildemente con Dios, pues también Dios está crucificado, que Dios camina con ellos como Dios liberador y que al final Dios será todo en todo.

No mucho más se puede decir, pero hay creyentes que tienen que decir esto. En definitiva dicen que "no pueden vivir ni autocomprenderse de otra manera" sin traicionar su honradez fundamental. Su fe en general y la fe en el Dios crucificado en particular es lo que les mueve a seguir caminando y, desde ese caminar, a creer que en el origen hay gracia y en el final hay plenitud.

\section{Notas:}

1. En El Salvador se ha desarrollado una vigorosa teologia del pueblo crucificado. Lo hizo magistralmente Monseñor Romero desde una perspectiva pastoral e I. Ellacurfa desde una perspectiva teológica. Véase lo que escribr sobre ello en Jesucristo liberador (San Salvador 1991) pp. 423-451.

2. Para ml no hay duda de que, debido a la época y a los lugares en que realizaron su formación teológica - las teolog/as de la secularización y de la muerte de Dios en el primer mundo de los años sesenta - y debido sobre todo a "la situación de teodicea" de América Latina, los télogos de la liberación más conocidos son bien conscientes del problema teologal. Baste recordar el libro de G. Gutierrez Hablar de Dios desde el sufrimiento del inocente. Una reflexión sobre el libro de Job (Lima 1986). 
3. He tratado brevemente de ambos temas en "Dios y los procesos revolucionarios", Diakonio 17 (1981) pp. 39-56 y Jesucristo Liberador, pp. 391-422.

4. Sobre la realidad primordial de esos veinte años puede verse Carta a las Iglesias, publicación quincenal de la UCA, y Marla López Vigil - Jon Sobrino, La matanza de los pobres (Madrid 1993). Sobre la interpretación teologica de esa realidad, puede verse lo que hemos escrito en el epílogo de ibid. pp. 355-370 y en el capítulo "El pueblo crucificado", Jesucrisio liberador, pp. 423-45I.

5. Permítaseme decir que mi ejemplar de este libro quedó materialmente cubierto con la sangre de Juan Ramón Moreno cuando introdujeron su cadáver en mi habitación la noche del 16 de noviembre de 1989, cuando asesinaron a seis jesuilas y dos trabajadoras de la UCA.

6. Muchas veces hemos citado las vigorosas palabras de don Pedro Casaldáliga ante la desaparición de pueblos enteros: "Señor, ipor qué los has abandonado?", en "Los indios crucificados. Un caso anónimo de martirio colectivo", Concilium 183 (1983) 387. Pues bien, con ser tan vigorosas - como lo eran las de Monseñor Romero- ni siquiera estas palabras pueden sustituir a la realidad, aunque nos ayuden a buscarla y a expresarla una vez encontrada. Los textos pueden llevar la realidad a su plenitud, si se les considera como su "símbolo real" en el sentido rahneriano. Pero sin realidad, digamos lo obvio, no hay texto. $Y$ el texto tendrá su fuerza en relación con la realidad, no en independencia de ella. Por ello, la teología nunca puede basarse sólo en otra teología, sino que en algún momento tiene que enfrentarse con y basarse en la realidad.

7. La teología de la liberación exige que se ausculten los signos de los tiempos, pero no sólo en cuanto realidades que caracterizan una epoca -acepción histórico-pastoral como se propone en GS 4-, sino en cuanto realidades en las que se expresa la presencia o los planes de Dios - acepción histórico-teologal como se propone en GS 11. Véase, J. L. Segundo "Revelación, fe, signos de los tiempos," Revisra Latinoamericana de Teología 14 (1988) 123-144; J. Sobrino "Los signos de los tiempos en la teologia de la liberación", en Varios, Fides quae per carriatem operatur (Bilbao 1989), pp. 249-269.

8. Como es sabido, Metz ha propuesto que la teología sea narrativa, lo cual significa remitir al menos a realidades - que van a ser narradas - antes que al concepto que de ellas se pueda extraer. Y el mismo Metz ha relacionado, y de forma muy eficaz, teologla y realidad al preguntarse cómo hacer teologla después de Auschwitz.

9. Aunque sea obvio, hay que recordar que las primeras elaboraciones teologicas, tanto del Antiguo como del Nuevo Testamento, estaban basadas en la realidad y -por definición- no eran ni podlan ser todavía reflexiones sobre textos. Hay un momento, pues, en que la leología se ve confrontada directamente con la realidad, como lo estuvo el primer jahvista o elohista, sea quien fuere $\longrightarrow$ el observador presocrático de la naturaleza.

10. "El acto o los actos de acceso del hombre a Dios no son los formalmente intelectivos, sino que son aquellos actos que física y realmente nos llevan efectivamente a El en tanto realidad absolutamente absoluta ... Dios es constitutivamente accesible en las cosas reales mismas. Jamás, ni en el acceso supremo de los grandes místicos, se accede a Dios sin las cosas o fuera de ellas: se accede siempre a Dios en las cosas. Las cosas reales son la presencia personal de Dios", El hombre y Dios (Madrid 1984), pp. 181 y 186. 
11. No analizamos ahora el alcance cuantitativo de ese cambio. ni la marcha atrás que se está operando ahora con la proliferación de sectas y de movimientos católicos afines. Pero hay que constatar que el cambio, muy importante, se ha dado y que se ha dado sobre todo en los movimientos populares liberadores.

12. Maria López Vigil, Muerte y vida en Morazán (San Salvador 31989), pp. 119.

13. Ibid., pp. $94 s$.

14. Ibid., p. 119.

15. Citado en J. Sobrino, I. Martín-Baro y R. Cardenal, La voz de los sin voz. La palabra viva de Monseñor Romero (San Salvador 198I) 454.

16. J. I. González Faus. La humanidad nueva (Santander ${ }^{6}$ 1984), p. 447.

17. Lo decisivo aquí no es el modelo filos6fico concrelo en que se expresa esa afinidad que salva: acercamiento-participación-asumpción de Dios de todo lo humano según la teologla griega, el sacrilicio del Hijo según la teología latina. Explicar cómo la asumpción de lo humano y el sacrificio causan salvación es pohlema de la razón filosófica y teológica, pero lo importante es recalcar el hecho mismo: sin alguna forma de afinidad entre lo divino y lo humano, no puede haber salvación.

18. Atanasio, el opositor de Arrio, dirfa por esta razón que "para nosotros serfa tan inútil que la Palabra no fuera el verdadero Hijo de Dios por naturaleza, como que no fuera verdaderamente came lo que asumi6", Contro Arrianos $/ I, 70$.

19. El Dios crucificado (Salamanca 1974), p. 348.

20. Véase el libro citado de J. Moltmann.

21. Véase L. Boff, Jesucrisło y la liberación del hombre (Madrid 1981). Por un lado habla de la cruz de Jesús, es decir, la cruz del Hijo, como evangelio, buena noticia, pp. 437-441, pero por otro no se decide a hablar del sufrimiento del Padre, pp. $405-422$.

22. Peter W. Gyves, "Carta de agradecimiento y solidaridad desde Estados Unidos", en Carra a las Iglesias 291 (1993), p. 10.

23. "El pueblo crucificado. Ensayo de soteriologfa histórica", Rèvista Latinoamericana de Teologio 18 (1989), pp. 305-333.

24. "¿Por qué sé ha de decir que Dios tuvo madre, padeció y murió, y no se dice, a la inverse, que el hombre que es Jesús es inmutable, inaccesible, inmortal, omnisciente y todopoderoso?", J. L. Segundo, "Disquisición sobre el misterio absoluto", Revista Latinoamericana de Teología 6 (1985), p. 215.

25. Vease Jesucrisio Liberador, pp. 294-296.

26. Carta de Ann Manganaro, religiosa norteamericana fallecida en mayo de este año. El texto íntegro puede verse en Carta a las Iglesias 283 (1993), p. 9.

27. No hay que pasar precipitadamente por alto la pregunta de los primeros cristianos sobre si la cruz de Jesús era algo malo o bueno, y, más en concreto, si y qué de bueno trala para ellos como seres humanos. En el Nuevo Testamento -y a lo largo de la historia- se desarrollaron diferentes modelos terricos para hacer comprensible como la cruz de Jesús pudo traer algo de bueno, la salvación. Pero sea cual fuere la capacidad explicativa de esos modelos, lo importante es la afirmacion en sf misma: la cruz (junto con la resurrección y toda la vida de Jesús) produjo salvación. Y más importante aún es el presupuesto: también la cruz, si es realidad de Dios, tiene que traer salvación. Véase lo que hemos escrito sobre ello en Jesucrisio liberador, pp.361-370.

28. Se ha llegado a decir que la única justificación que puede dar Dios ante el mal es que no existe. 
29. "¿Donde estabas tri cuando fundaba yo la tierra?" (Job 38, 4). "El ha hecho todas las cosas apropiadas a su tiempo; tambien ha puesto el afán en sus corazones, sin que el hombre llegue a descubrir la obra que Dios ha hecho de principio a fin" (Qoh 3,11). Y en términos operativos, dice Jeremlas: "Habla en mi corazón algo asi como fuego ardiente, prendido en mis huesos, y aunque yo trabajaba por ahogarlo no podía" (Jer 20,9). En el caso de Jesús, la respuesta eficaz es la resurrección.

30. La matanza de los pobres,p. 249.

31. Desde una perspectiva té6rica lo hemos analizado en "La experiencia de Dios en la Iglesia de los pobres", en Resurrección de la verdadera Iglesia (Santander 1981/San Salvador 1986), sobre todo pp. 143-156. Y desde una perspectiva más histórica en “"Conllevaos mutuamente'. Análisis teológico de la solidaridad cristiana", en El principin misericordia (Santander 1992/San salvador 1993), pp. 239-245.

32. Esto to he analizado en un escrito reciente, no publicado, Ignacio Ellocuría, el hombre y el cristiano. "Bajar de la cruz al pueblo crucificado" 31-37.

33. Recordemos lo que dice Rahner sobre las afirmaciones escatológicas: expresan la plenitud desde lo que la historia puede dar de sí. Y siguiendo la misma lógica pudiera decirse que las afimaciones protológicas expresan en plenitud el impulso de la gracia que encontramos en la historia.

34. "Camino que uno es", en Cantares de la entera libertad (Managua 1984), p. 47.

35. Ibid., p. 48. 